Alicante Journal of English Studies 30 (2017): 187-212

\title{
English lexical items in Egyptian Arabic. Code-switching or borrowing?
}

\author{
Małgorzata Kniaź \\ Jagiellonian University \\ malgorzata.kniaz@gmail.com
}

\begin{abstract}
The study aims to answer the question of whether lone English items that occur in Arabic-English code-switching are borrowings or code-switches. This is based on empirical data collected at the American University in Cairo. The data were analyzed within the framework of the Matrix Language Frame model. 3443 bilingual projections of complementizer (CP) were investigated. They were divided into two types: (1) CPs with Arabic as the Matrix Language (ML) and (2) CPs with English as the ML. The analysis shows a clear discrepancy between categories of items used in the two types. In Arabic CPs, the most frequently switched category concerns English nouns related to the field of study and academic life as well as Standard Arabic in monolingual discourse. The interviews conducted with the participants in the study revealed that they were mostly used due to the lack of Arabic equivalents at the speakers' disposal. In English CPs, mainly Arabic conjunctions and discourse markers appear. We claim that this categorial and functional variation between Arabic and English results from the linguistic situation in the Arab world. For bilingual speakers in Arabic diglossic communities, educated in schools with instruction in English and non-proficient in Standard Arabic, English items are the only means to communicate in many fields. Such items become part of their mental lexicon and thus should be considered as borrowings even if they are not established loans.
\end{abstract}

Keywords: Arabic-English code-switching, borrowing, Egypt 


\section{Aim of the study}

Code-switching, defined here after Li (2013: 360) as "a cover term to describe a range of linguistic behavior that involves the use of more than one language or language variety in the same interaction", involves switching between both lone items and longer clusters. While multi-word insertions are unquestionable examples of code-switching, the status of lone items arouses controversy. In the literature on code-switching, lone items that are not established loanwords are in general treated as twofold, either as code-switches or nonce borrowings (for further explanation on the concepts see Section 3 ). The distinction between the two is usually based on grammatical factors.

The present study ${ }^{1}$ deals with lone English items that occur in Arabic-English codeswitching in the speech of students from the American University in Cairo. Our aim is to answer the question of whether such items are instances of code-switching or borrowing. In our data, nouns represent the most frequently switched category of lone items. At first glance, they can be classified as neither established loans, since they are not used by monolingual speakers, nor cultural loans that represent concepts and objects unfamiliar to Arabic speakers. However, a more detailed analysis, also taking into account sociolinguistic and pragmatic factors, reveals that their status is not so obvious. We claim that a lot of English items serve as established loans although they are not recognized by the whole Egyptian community. The reason is the linguistic situation in Egypt, the growing prestige of English which affects the education of the higher classes, and consequently the lack of proficiency in Standard Arabic among a specific sector of the Egyptian community.

\section{The linguistic situation in the Arab world}

\subsection{Diglossia}

The linguistic situation in the Arab world is usually referred to as diglossia. According to Ferguson's (1959) classical concept, diglossia implies that in a speech community two complementary varieties of a language coexist. These varieties fulfil different functions and are employed in different circumstances. The 'high' variety is primarily used for written purposes. As the language of literary heritage, it is highly standardized and enjoys a great deal of prestige. The 'low' variety, spoken in informal settings, is less prestigious and not standardized in terms of prescriptive grammars and dictionaries. In Arabic speech communities, diglossia includes Standard Arabic, unified throughout the whole Arab world, and a variety of vernaculars. Standard Arabic stands for the high variety. It is the language of high culture, literature, press and, importantly, the Koran and Islamic heritage which gives Standard Arabic the status of a sacred language within the Islamic community. Diverse vernaculars represent the 'low' variety. They are used in everyday communication and lack prestige attached to Standard Arabic. An important factor that sets Standard and vernacular Arabic apart from each other is their acquisition. Standard Arabic is acquired only through formal education. Vernaculars, on 
the other hand, are the Arabs' first language, i.e. their mother tongue, irrespective of their class, level of education, religious affiliation or profession. Thus, proficiency in Standard Arabic, which translates into the ability to read and write, is only achieved by attending schools in which Standard Arabic is taught. In Egypt, the pursuit of Standard Arabic is gradually becoming weaker and weaker due to significant linguistic changes that arose from the growing interest in English and the emergence of bilingual codeswitching.

\subsection{English}

Arabic-English code-switching in Egypt is a recent phenomenon. It emerged as a result of globalization and the open door policy initiated in the 1970s. Economic transformation paired with the partial privatization of the education system led to the growing popularity of private and international schools with instruction in English. Attending such schools that assured proficiency in English and consequently well-paid jobs in private companies (Schaub, 2000), became the common pursuit among the upper classes. English evolved into "the uncontested language of work and socializing in upper-middle class circles" (Koning, 2009: 61) and a hallmark of well-to-do Egyptians. Thus, mastery of English is a significant social marker supported by the strong stratification of the society.

The prevalence of English in the education of the upper classes has a great impact on the Egyptian linguistic landscape. In the majority of private and international schools with instruction in English, learning Arabic is not compulsory, or it is perceived as an unpleasant necessity (see Galegher, 2012). Their graduates, as Mehrez (2010: 210) points, constitute a young elite alienated from their own cultural heritage; "they all speak the vernacular, but for all intents and purposes they represent an illiterate elite where Arabic language and culture are concerned". As a result, English - as a social marker that affords a privileged position in the labor marker - undermined the former position of Standard Arabic to become the most important linguistic capital in Egypt. Standard Arabic remains the domain of low-paid employees in the state administration and schooling (Haeri, 1997).

\subsection{Code-switching}

One of the consequences of the social prestige of English, its prevalence in the wellpaid private sector and English-oriented education is the emergence of bilingual codeswitching that is used as a form of in-group, private and professional, communication among the upper classes.

Nevertheless, code-switching is not a new phenomenon in Egypt. The sharp dichotomy between Standard Arabic and vernaculars has significantly weakened since the introduction of universal education in the 1950s and the dissemination of Standard Arabic nationwide. In actual language use, native speakers tend to combine elements from both varieties in a single speech event. This phenomenon is usually referred to as Educated Spoken Arabic (Mitchell, 1986), 'āmmiyyat al-mu aqqafin (colloquial of the 
educated) (Badawi, 1973), mixed styles (Mejdell, 2006), multigossia (Hary, 1996), or diglossic code-switching (Bassiouney, 2006; Boussofara-Omar, 2003).

Diglossic code-switching serves as a spoken equivalent of Standard Arabic. It is used in formal and semi-formal settings to discuss issues related to politics, culture, science, religion etc. Standard Arabic, as a primarily written variety, is perceived as too artificial to provide natural oral communication. Vernaculars, on the other hand, cannot fulfil all communicative needs, especially those related to more serious topics that go beyond the domain of everyday life due to, among others, the lack of the necessary vocabulary.

Thus, the linguistic situation in Egypt points to two things. Firstly, people who do not get a formal education in Standard Arabic - i.e. the majority of graduates of schools with instruction in foreign languages - are able to communicate in Arabic to a limited extent. Second, fields associated with the high variety in Arabic are accessible to them via English. Thus, a lot of English terms in fact became part of their mental lexicon i.e. they are the only ones that are accessible during the language production process. This may indicate that this particular group among Egyptian society is not diglossic in fact (as far as the classical notion of diglossia is concerned). In their speech, the functions of the high and low variety are fulfilled by two unrelated linguistic codes Egyptian Arabic and English.

\section{Borrowing vs. code-switching}

In the literature on code-switching, inserted lone items are treated as twofold. According to Myers-Scotton $(1992 ; 1993 ; 2006)$ code-switching and borrowing are closely related processes. Therefore, single items should not be excluded from codeswitching. Poplack and her associates (Budzhak-Jones and Poplack, 1997; Poplack and Meechan, 1998; Poplack et al., 1988; Poplack et al., 1989; Sankoff et al., 1990), on the other hand, make a strict distinction between borrowing and code-switching. Borrowing, as opposed to code-switching, involves the grammatical structure of one language. Thus, non-integrated lexical items are considered as nonce borrowings. These two different approaches to borrowing derive mainly from different theoretical approaches to code-switching developed by Poplack and Myers-Scotton.

\subsection{Borrowing and code-switching as discrete processes}

Poplack defines code-switching as "the juxtaposition of sentences or sentence fragments, each of which is internally consistent with the morphological and syntactic (and optionally, phonological) rules of the language of its provenance" (Poplack, 1993: 255). In other words, code-switching implies alternation between two linguistic codes. Switched elements and clusters observe the rules of the donor language throughout the discourse. Code-switching is controlled by two universal constraints. According to the free morpheme constraint, "codes may be switched after any constituent in discourse provided that constituent is not a bound morpheme" (Poplack, 1980: 585-86). The 
equivalence constraint states that code-switching is allowed as long as the juxtaposition of the elements from the two languages does not violate the syntactic rules of either language (Poplack, 1980: 586).

However, the universality of these constraints was questioned in many studies including those concerning code-switching with Arabic. Counterexamples of singly occurring lexical items were encountered in a variety of language pairs - Arabic and French (Bentahila and Davies, 1983); Arabic and Dutch (Nortier, 1990); as well as Arabic and English (Al-Khatib, 2003; Atawneh, 1992; Bader, 1995; Bader, 1998; Bader and Minnis, 2000; Mustafa and Al-Khatib, 1994). In Arabic-English code-switching, counterexamples to the free morpheme constraint include, among others, instances of mixed verbs composed of Arabic affixes and an English verb stem, e.g. bitride 'she rides' (Atawneh, 1992: 233) or nouns modified by the definite article al/il, a bound morpheme in Arabic. A typical violation of the equivalence constraint is exemplified by mixed adjectival phrases, e.g. nose $\dot{g} \bar{l} r$ 'a small nose' (Atawneh, 1992: 230) where the word order follows the grammatical rules of Arabic and conflicts with the rules of English.

In response, Polack states that such cases are not instances of code-switching but borrowing. As opposed to code-switching, in borrowing only one linguistic system operates which results in the morphological and syntactical (though not necessarily phonological) integration of an inserted lexical item into the recipient language. Importantly, borrowing is not restrained to established loanwords incorporated into the lexicon of the recipient language and widely used by monolingual speakers. The use of non-established, non-phonologically integrated nor recurrent lexical items is termed nonce borrowing which refers to as "a one-off occurrence resorted to by the speaker" (Poplack et al., 1988: 58). Although nonce borrowings are usually not recognized by monolinguals, they are akin to established loanwords in terms of linguistic production. The so-defined borrowing and code-switching phenomena lead to the assumption that "lone major-class content words of one language incorporated in discourse of another are almost always borrowings" (Poplack and Meechan, 1998: 135). This hypothesis was tested in a variety of studies (Adalar and Tagliamonte, 1998; Budzhak-Jones, 1998; Eze, 1998; Turpin, 1998) that applied the comparative variationist methodology to examine syntactic context in which lone lexical items appear. These studies confirm that such items systematically behave as their counterparts in the other language and established loans. This entitles to conclude that they are cases of borrowing since only one linguistic structure is active at a time. Thus, according to this point of view, the only real cases of single-word codeswitches will be those which are not morphologically and syntactically incorporated into the recipient language.

\subsection{Borrowing and code-switching as a continuum}

Myers-Scotton, on the other hand, states that code-switching and borrowing are not different processes but part of the same continuum. This statement arises from an idea regarding the insertional nature of code-switching. According to Myers-Scotton's Matrix Language Frame (MLF) model in bilingual production, there is always one 
dominant language at work and that is the matrix language (ML). The constraints on code-switching are based on the asymmetrical distribution between system and content morphemes. System morphemes, as it was originally postulated (Myers-Scotton, 1993), derive from the ML, whereas content morphemes may come from both the matrix and the embedded language (EL). EL content morphemes are inserted into the ML, which provides the grammatical frame. Thus, non-attested in the ML EL lone lexical items are always framed by the ML since only the ML system operates.

The notion of continuum between borrowing and code-switching is based on the premise that code-switching takes an active part in introducing loanwords into the ML. However, it does not automatically categorize all lone lexical items inserted into the ML as cases of code-switching. Myers-Scotton makes a distinction between cultural loans, core borrowed forms and code-switching. Cultural loans are typical examples of borrowing. They refer to objects and concepts previously non-existent in the ML. Filling lexical gaps, they enter the ML lexicon abruptly and are widely used by both bilinguals and monolinguals who may not be aware of their foreign origins. As such, cultural loans, according to Myers-Scotton (1993: 173), ought to be excluded from code-switching as a phenomenon. Core loans, on the other hand, stand for objects and concepts already existing in the ML. Some of them may gradually become conventionalized code-switches due to their prestige and, eventually, part of the ML lexicon as established loans. Thus, code-switching is "the gate by which content morphemes as core B [borrowed] forms enter the ML" (Myers-Scotton, 1993: 174). To distinguish between code-switching and borrowing, Myers-Scotton proposes two criteria - predictability and frequency. Core borrowing forms, in contrast to codeswitching forms, show a high frequency of occurrence and are relatively predictable; "It is not that a B [borrowed] form must recur, it is that CS [code-switched] form must not recur in order to be a CS form" (Myers-Scotton, 1992: 36, original emphasis). Specifically, content morphemes that appear at least three times in a relatively large corpus should be categorized as core borrowed forms (Myers-Scotton, 1993: 207).

Thus, both Poplack and Myers-Scotton utilize structural integrity to confirm the validity of the two models of code-switching. We agree with Myers-Scotton that codeswitching and borrowing constitute a continuum. Not all single words of foreign origin automatically comprise the category of borrowings and therefore should be excluded from code-switching. Nevertheless, we believe that in Egypt not all non-established borrowings can be classified as belonging to code-switching. Secondly, the criterion here should be contextual/functional rather than purely structural; the local context as well as the speakers' linguistic background should be included in the analysis.

\subsection{Borrowing vs. code-switching in bilingual speech with Arabic}

Most studies on code-switching with Arabic do not differentiate between the two phenomena, treating lone lexical items not established as loanwords in Arabic as codeswitches (Al-Mansour, 1998; Atawneh, 1992; Bentahila and Davies, 1983; Bentahila and Davies, 1991; Boumans, 1998; Hussein and Shorrab, 1993; Mohamed, 1989; Myers-Scotton et al., 1996; Nortier, 1990; Sallo, 1994). 
Mustafawi (2002) and Rouchdy (1992), on the other hand, make such a distinction, although in each case for different reasons. The first study takes a variationist approach to code-switching to test the nonce borrowing hypothesis. It investigates the morphosyntactic behaviour of lone English-origin nouns focusing on patterns of determination, gender assignment and word order - i.e. grammatical contexts incongruent in Arabic and English. The comparison of ambiguous lone nouns with established loans and native Arabic nouns in the contexts under investigation show that lone items are used in a similar way to Arabic nouns and established loans. This supports the nonce borrowing hypothesis and suggests, according to Mustafawi, that singly occurring items should be treated as borrowings.

A similar differentiation between borrowing and code-switching was adopted in Rouchdy (1992). However, in contrast to the purely syntactic approach of variationist studies, Rouchdy states that the use of code-switching vs. borrowing is determined by two factors - the linguistic system of the languages involved and the social context. A variable that seems to have a significant impact on the issue is the speaker's level of education. It determines both the degree of phonological adaptation and the patterns used. Semi-educated speakers tend to resort to borrowing whereas educated speakers use code-switching. Thus, the clause "She left her in the car" may be uttered as either

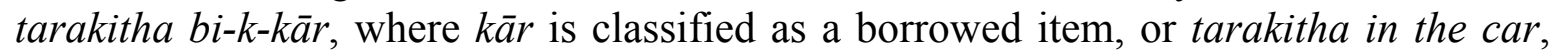
where the prepositional phrase in the car is defined as code-switching. The former would be typical of the semi-educated and the second of the educated. The same applies to pluralization patterns. Educated speakers avoid using the Arabic plural suffix $-\bar{a} t$ with English nouns, which is, on the other hand, the most common type of pluralization among semi-educated speakers (e.g. parking lots vs. barkin lottāt) (Rouchdy, 1992: 41). On the other hand, the semi-educated pronounce borrowed items closely to the English phonetics. In the speech of the educated, borrowed items are usually phonologically integrated with Arabic (Rouchdy, 1992: 42).

Thus, in both studies, the integration of inserted constituents is a decisive factor for the differentiation between code-switching and borrowing. Integrated items are ad hoc classified as instances of borrowing. However, Heath's study (1989) shows that in Moroccan Arabic there are items that function as loanwords, but show partial or no morphological integration. For instance, some French verbs introduced to Moroccan Arabic during the colonial period remained unintegrated in terms of inflection while more recent loans manifest some inflectional integration. This finding indicates different patterns of borrowing in Moroccan Arabic. Interestingly, in Moroccan ArabicFrench code-switching, different patterns of code-switching are found as well. Bentahila and Davies' study (1992) on two generations of Moroccans reveals that balanced bilinguals - i.e. the older generation - tend to use inter-sentential codeswitching, while the younger generation, with a lesser command of French, but more proficient in Standard Arabic, use intra-sentential code-switching. This may suggest that proficiency in both languages, as also suggested by Rouchdy, affects patterns of both code-switching and borrowing. Thus, we hypothesize that a lot of lone items that appear in the speech of fluent bilinguals in Egypt should be classified as instances of 
borrowing. However, this assumption is based not solely on bilinguals' linguistic proficiency. We claim that borrowing is also motivated by the linguistic situation in Egypt.

\section{Data}

The study is based on the data collected from students of the American University in Cairo in 2015. The AUC is the most prestigious and expensive university in Egypt with instruction in English. It attracts mostly fluent bilinguals from the upper classes graduated from private and international schools with instruction in foreign languages. Graduates of state schools who won scholarships at the university are subject to intensive language instruction after their admission. At the start of the study, students are supposed to have a fluent command of English.

For the present study, we used approximately 14 hours of recordings that consisted of eight group interviews designed to collect speech samples. The duration of the interviews ranged from 45 to 170 minutes. In each, at least two participants took part. The interviews took the form of relaxed conversation. To minimize 'the observer's paradox' and get as much natural linguistic data as possible, we engaged the participants in conversation with each other. They discussed a variety of topics such as the linguistic situation in Egypt, code-switching, education, social inequalities, culture, religion, economy, sexual harassment, hobbies, family life, etc.

\section{Methodology}

The data were analyzed within the framework of the MLF model. Since the 1990s it has become the most frequently used theory in the study of code-switching. For the purpose of the present study, the MLF model is a more promising framework for analysis than the variationist approach. The latter consists of comparing the grammatical context of lone items from language 2 to that of language 1 and established loans. Thus, its application of the latter must end with the conclusion that all lone items are nonce borrowings since they almost always show morphological and syntactic integration with the recipient language. Otherwise the universality of the constraints formulated by Poplack will be questioned, which in fact was raised in a variety of studies on codeswitching with Arabic.

The validity of the MLF model was questioned as well - e.g. in Aabi (1999) and AlEnazi (2002). However, this is because those studies applied the MLF model in its original formulation, strictly adhering to the restrictions on system morphemes. As a result, in different data sets, system morphemes from the EL were detected, which is inconsistent with the main premise of the MLF model. Nevertheless, the asymmetry between the distribution of system and content morphemes does not assume that only content morphemes are allowed to be inserted into the ML. The Abstract Level and the 
4-M model, developed as MLF sub-models (see e.g. Myers-Scotton and Jake, 2009), elaborate on morpheme classification with reference to their syntactic roles and distribution, admitting two types of system morphemes - early and bridge - to occur in bilingual constituents. Studies that incorporate these amendments into the analysis (Alenezi, 2006; Al-Rowais, 2012; Okasha, 1999) confirm the validity of the MLF model in bilingual code-switching with Arabic. Furthermore, the MLF model does not automatically exclude integrated items from code-switching. Given that the MLF model is insertional, both code-switches and borrowed items should be subject to morphological and syntactic integration.

The data were divided into projections of complementizer (CP) - the units of analysis in the MLF model. The individual CPs were further divided into four main categories: (1) Arabic monolingual CPs, (2) CPs with Arabic as the ML, (3) English monolingual CPs, and CPs with English as the ML. Any CPs with composite ML - i.e. CPs in which both languages simultaneously provide the grammatical frame (see e.g. Myers-Scotton, 1998) - were excluded from the analysis. ${ }^{2}$ Lone items in bilingual CPs were subject to further analysis which included both singly occurring and recurrent ones. We did not exclude recurrent items (which Myers-Scotton classifies as core borrowed forms) since a lot of them seemed to occur as a consequence of linguistic accommodation to the interlocutor. Lone items were categorized according to the type of morphemes they represent. The following categories were distinguished: adjectives, adverbs, conjunctions, definite articles, discourse markers, nouns, personal pronouns, prepositions and verbs. The goal of this procedure was to find any possible differences between the two types of CPs since they may translate into functional differences between the two languages. The analysis also includes recurrent compound nouns. In the MLF model inserted constituents are not necessarily single words. A constituent can be any syntactic unit, either a lexical item (e.g. a noun) or a phrase. Constituents of more than one word are called 'EL islands'. Such islands are well-formed according to the grammatical rules of the EL. Within this approach, compound nouns should be treated as EL islands. However, their recurrence and their lack of Arabic equivalences in the data indicate that they are perceived as single units. For that reason, we differentiate between this particular kind of compound noun and the 'real' EL islands that were investigated at the final stage of the study.

\section{Results of the study}

Table 1 shows the distribution of the categories found in particular interviews. AR M stands for monolingual Arabic CPs, AR ML - CPs with Arabic as the ML, ENG M monolingual English CPs, and ENG ML - CPs with English as the ML. The data differ in the total number of CPs ranging from 865 in interview 1 to 3575 in interview 6 due to differences in the duration of the interviews. They are also significantly diversified in terms of patterns used. Interview 8 exhibits the smallest number of CPs with English providing the grammatical frame, namely seven CPs (five monolingual and two mixed) which constitutes 0.73 percent of the total $\mathrm{CP}$ number. The highest number of CPs 
controlled by English is found in interview 3, with 596 CPs (56,65 percent). Nevertheless, the quantitative analysis of the whole data shows two features common to all data sets. The first one is the participants' preference for monolingual CPs. The second one is their preference for Arabic over English CPs within monolingual CPs. Out of the total number of $13513 \mathrm{CPs}, 10170 \mathrm{CPs}(75.26 \%)$ are either monolingual Arabic (6578) or monolingual English (3412). Mixed CPs that were subject to analysis number 3443 (2076 with Arabic and 1367 with English as the ML) which constitutes approximately 25 percent (15.36\% and $10.12 \%$ for Arabic and English respectively).

\begin{tabular}{|c|c|c|c|c|c|c|}
\hline & & $\begin{array}{l}\text { total } \\
\text { CP }\end{array}$ & AR M & $\begin{array}{l}\text { AR } \\
\text { ML }\end{array}$ & $\begin{array}{l}\text { ENG } \\
\text { M }\end{array}$ & $\begin{array}{l}\text { ENG } \\
\text { ML }\end{array}$ \\
\hline \multirow{2}{*}{$\begin{array}{l}\text { interview } \\
1\end{array}$} & $\mathrm{~N}$ & \multirow[t]{2}{*}{865} & 556 & 185 & 94 & 30 \\
\hline & $\%$ & & $64,28 \%$ & $21,39 \%$ & $10,87 \%$ & $3,47 \%$ \\
\hline \multirow{2}{*}{$\begin{array}{l}\text { interview } \\
2\end{array}$} & $\mathrm{~N}$ & \multirow[t]{2}{*}{928} & 402 & 121 & 287 & 118 \\
\hline & $\%$ & & $43,32 \%$ & $13,04 \%$ & $30,93 \%$ & $12,72 \%$ \\
\hline \multirow{2}{*}{$\begin{array}{l}\text { interview } \\
3\end{array}$} & $\mathrm{~N}$ & \multirow[t]{2}{*}{1052} & 350 & 106 & 391 & 205 \\
\hline & $\%$ & & $33,27 \%$ & $10,08 \%$ & $37,17 \%$ & $19,49 \%$ \\
\hline \multirow{2}{*}{$\begin{array}{l}\text { interview } \\
4\end{array}$} & $\mathrm{~N}$ & \multirow[t]{2}{*}{1264} & 885 & 244 & 76 & 59 \\
\hline & $\%$ & & $70,02 \%$ & $19,30 \%$ & $6,01 \%$ & $4,67 \%$ \\
\hline \multirow{2}{*}{$\begin{array}{l}\text { interview } \\
5\end{array}$} & $\mathrm{~N}$ & \multirow[t]{2}{*}{2047} & 1002 & 281 & 607 & 157 \\
\hline & $\%$ & & $48,95 \%$ & $13,73 \%$ & $29,65 \%$ & $7,67 \%$ \\
\hline \multirow{2}{*}{$\begin{array}{l}\text { interview } \\
6\end{array}$} & $\mathrm{~N}$ & \multirow[t]{2}{*}{3575} & 1757 & 611 & 706 & 501 \\
\hline & $\%$ & & $49,15 \%$ & $17,09 \%$ & $19,75 \%$ & $14,01 \%$ \\
\hline \multirow{2}{*}{$\begin{array}{l}\text { interview } \\
7\end{array}$} & $\mathrm{~N}$ & \multirow[t]{2}{*}{2825} & 1084 & 300 & 1146 & 295 \\
\hline & $\%$ & & $38,37 \%$ & $10,62 \%$ & $40,57 \%$ & $10,44 \%$ \\
\hline \multirow{2}{*}{$\begin{array}{l}\text { interview } \\
8\end{array}$} & $\mathrm{~N}$ & \multirow[t]{2}{*}{957} & 722 & 228 & 5 & 2 \\
\hline & $\%$ & & $75,44 \%$ & $23,82 \%$ & $0,52 \%$ & $0,21 \%$ \\
\hline \multirow[t]{2}{*}{ Total } & $\mathrm{N}$ & \multirow[t]{2}{*}{13513} & 6758 & 2076 & 3412 & 1367 \\
\hline & $\%$ & & $50,01 \%$ & $15,36 \%$ & $25,25 \%$ & $10,12 \%$ \\
\hline
\end{tabular}

Table 1: Overall distribution of monolingual and bilingual CPs

Single constituents in mixed CPs with Arabic as the ML (including compound nouns) number 1843. In CPs with English as the ML, single constituents amount to 
1116. Tables 2 and 3 display the type and frequency of constituents that constitute at least $0.5 \%$ of all constituents in Arabic and English CPs respectively in order of their frequency of occurrence. The distribution of particular types of morphemes differs significantly. The most frequently inserted morphemes are nouns followed by adjectives, verbs and adverbs in CPs with Arabic as the ML, and conjunctions, discourse markers, adverbs and nouns in CPs with English as the ML.

\begin{tabular}{|l|l|l|}
\hline & $\mathbf{N}$ & $\%$ \\
\hline nouns & 1318 & $71,51 \%$ \\
\hline $\begin{array}{l}\text { compound } \\
\text { nouns }\end{array}$ & 164 & $8,90 \%$ \\
\hline adjectives & 162 & $8,79 \%$ \\
\hline verbs & 68 & $3,69 \%$ \\
\hline adverbs & 61 & $3,31 \%$ \\
\hline conjunctions & 29 & $1,57 \%$ \\
\hline prepositions & 15 & $0,81 \%$ \\
\hline Total & 1817 & 98,58 \\
\hline
\end{tabular}

Table 2: Mixed CPs with Arabic as the ML

\begin{tabular}{|l|l|l|}
\hline & $\mathbf{N}$ & $\%$ \\
\hline conjunctions & 437 & $39,16 \%$ \\
\hline $\begin{array}{l}\text { discourse } \\
\text { markers }\end{array}$ & 314 & $28,14 \%$ \\
\hline adverbs & 196 & $17,56 \%$ \\
\hline nouns & 87 & $7,80 \%$ \\
\hline $\begin{array}{l}\text { personal } \\
\text { pronouns }\end{array}$ & 37 & $3,32 \%$ \\
\hline adjectives & 12 & $1,08 \%$ \\
\hline prepositions & 12 & $1,08 \%$ \\
\hline definite articles & 7 & $0,63 \%$ \\
\hline Total & 1102 & 97,69 \\
\hline
\end{tabular}

Table 3: Mixed CPs with English as the ML

6.1. Mixed CPs with Arabic as the ML 
Nouns constitute 71.5 percent of the total number of single-constituent insertions in CPs with Arabic as the ML. If we add compound nouns, the percentage increases to 80.4 percent. The majority of the inserted nouns are related to academic life, professional career, social and political issues, culture as well as geographical names (e.g. course, student, dorm, professor, English, media, sexual harassment, social class, high school etc.) In general, these are terms that are acquired through formal education and associated with Standard Arabic in monolingual discourse. Most of them, whether single or compound nouns, are used as bare forms fully integrated morphologically and syntactically with Arabic, which is exemplified in (1) and (2) below. In (1), program lacks an indefinite article which is absent in Arabic. In (2), middle class is modified by the Arabic article $i l$-, the verb $i$ tafa 'to disappear' is used in the feminine form. The latter indicates that the speaker knows the Arabic equivalent of class - abaqa which is feminine. However, the knowledge of Arab equivalents is not obvious. It can be tested solely when the noun is modified by a determiner, adjective, verb or in possessive constructions with $b_{i t a}$ ' 'of' - which is subject to declination according to gender and number - provided that the Arabic equivalent is feminine. In such contexts, complete syntactic integration is not always observed. In (3) economy is used with the feminine demonstrative $d i$ and the feminine form of the verb assar 'to affect' although the Arabic equivalent iqti $\bar{a} d$ is masculine. In (4) graduation project, which in Arabic is masculine (mašr $\bar{u}^{\prime} t a$ arru ), is followed by the feminine form of bitā'.

(1) kunn i na mašyīn taba' program mu'ayyan were.1PL we going accordance program specific

We were proceeding according to a specific program.

(2) il-middle class 'and-ina i taf-it ta'rīban the-middle class with-our disappeared-PRFX.3f approximately

Our middle class has almost disappeared.

(3) fa b-adris izzāy ba'a l-economy di bi-t'assar 'a n-nās so ASP-learn.1s how so the-economy this.FEM ASP-affect.3fs on the-people So I learn how this economy affects people.

(4) 'and i graduation project bitā' it con simulation with-my graduation project of.FEM.SG con simulation I'm doing a graduation project on CON simulation.

The integration of nouns with Arabic is absent in plural forms and infrequently observed in forms modified by the article $i l$ - where its assimilation to the first phoneme of the noun is required. Plural forms, both single and compound nouns, are inserted with the suffix $-s(5)$ :

(5) ana kull illi 'and-i numbers u consumer trends I all that with-me numbers and consumer trends All that I have is numbers and consumer trends. 
There is one exception. The noun courses is sometimes pluralized with the Arabic suffix -ât. Interestingly, both forms may be used by the same speaker, as it is in (6) and (7):

(6) b-ya du kulli 1- agāt wi-l-courses aw il-classes bita't-um bi-1-English ASP-they take all the-things and the-courses or the-classes of.FEM-their in-the-English They take all things and courses or their classes in English.

(7) $\mathrm{mu}^{6}$ am il-kurs-āt bi-1-English majority the-course-SFX.PL in-the-English The majority of the courses are in English.

The phonological assimilation of $i l$ - involves so called sun letters $(t, \quad, d, \quad, r, z$, $s, \check{s}, \quad, \quad, \quad, l, n)$. Whenever the article is followed by one of these consonants the $l$ in the article assimilates to it which results in a doubled consonant. Although the assimilation (8) appears on a regular basis, there are quite a few instances where it is not observed $(9,10)$. The reason for not adhering to the assimilation rules is not obvious. It is certainly determined by neither particular items nor consonants. Even high frequently used items, such as social class or topic, appear in the speech of some participants with unassimilated articles. This may indicate that some speakers prefer not to assimilate the article to English nouns. However, this assumption requires a different research design to allow its verification.

(8) wi ma-fí-š contradiction ma bēn is-science wi r-religion and NEG-there is-NEG contradiction PART between the-science and the-religion There is no contradiction between science and religion.

(9) bass il-struggle a al lamma gīt AUC but the-struggle happened.3ms when came.1s AUC The struggle happened when I came to AUC.

(10) izzāy il-filūs bi-t ušši u ti la‘ (.) il-stock market how the-money ASP-enters.z3f and go-out.3f the-stock market How money goes into and out of the stock market.

Adjectives are inserted as bare forms not observing the gender or number congruence with the noun when required in Arabic. They usually act as predicates, which is exemplified in (11) and (12). In both CPs, Arabic requires adjective inflection for the plural in (11) and feminine in (12). When used as attributives, adjectives follow the noun adhering to the Arabic word order (13). They are also modified by the definite article (14) if it is obligatory in Arabic.

(11) i na miš 'ayzīn yib'u cosmopolitan we NEG modal_of_desire.PL are.3 cosmopolitan We do not want to be cosmopolitan.

(12) fa hiyya rural 'awi 
so she rural very

So it's very rural.

(13) aw yib'a fîh ina'àt physical ma bēn rāgil u sitt or is.3MASC there_is fights physical PART between man and woman Or there are physical fights between a man and a woman.

(14) ana b-a ibb iš-ša 'r is-straight wi š-ša' $r$ il-făti I ASP-like the-hair the-straight and the-hair the-fair I like the straight hair and the fair hair.

Out of 68 verbs recorded in the data 56 take an Arabic inflection (15). The remaining 12 are inserted as bare forms. Integration with the Arabic conjugation or its lack seems to depend on the grammatical context in which a verb occurs. For instance, the third plural forms are inflected with the prefix, but not with the suffix $-u$ marking a plural. The difference between Arabic and English verbs in the plural is apparent in (16) - the verb accommodate is inflected only with the prefix yi- while the preceding verb byi awlu 'they try' with both the prefix $y i$ - and the suffix $-u$. However, the plural suffix appears with English nouns that are used as verbs (17).

(15) ana kamān ha-a-accept il-maw $\quad \bar{u}^{‘}$ da I also FUT-PFX.1 s-accept the-matter this I'll also accept this matter.

(16) inn professors b-yi- awl-u yi-accommodate li everyone that professors ASP-PFX-try-SFX.3PL PFX-accommodate to everyone That professors try to accommodate to everyone.

(17) wi ba'ū b-yi-target-u il-artists and began.3PL ASP-PFX.3ms-target-SFX.3PL the-artists And they began to target the artists.

\subsection{Mixed CPs with English as the ML}

As opposed to CPs with Arabic as the ML, in CPs with English as the ML nouns come only fourth. However, the relatively high position of nouns is due to interview 1 in which 53 nouns out of 87 appear mostly in one participant's utterances. A total of 51 of them refer to objects and concepts related to Arabic and Islamic culture. They seem to be used for two reasons. First, often their English equivalents may connote slightly different meanings, e.g. musalsalāt, which stands for TV shows produced for Ramadan, is usually translated as 'soap operas' although the terms refer to distinct socio-cultural phenomena. The second reason seems to be more of religious nature. Religious discourse on Islam in the Arab world is believed to be delivered in Standard Arabic. In the interview in question, one of the participants discussed religious issues primarily in English due to, as she admitted, her insufficient knowledge of Standard Arabic. The use of Arabic religious terms was a way to authenticate the message and emphasize her religious devotion. Such terms are introduced as either lone items or EL islands, e.g. 
āyat il-kursi (The Throne Verse), sayyidina mu ammad (our lord Muhammad). While inserted as lone items they are mostly morphologically and syntactically integrated to English which includes, for instance, their modification by the articles $a$ (18) and the (19) or the plural suffix $-s$ (20):

(18) today they tell you that a woman cannot be part of the mosque, cannot be an imām (imam), cannot be a še $-a$ (scholar trained in the religious sciences-FEM)

(19) the šē was very angry with me

(20) my mother has always been partial to the magribi-s (Morrocans)

In the remaining interviews, the number of nouns ranges from zero to ten with an average of approximately five nouns per interview. The low number of lone nouns goes hand in hand with an even lower number of adjectives (1.08\%) and a complete lack of inserted verbs - i.e. the most frequent categories in CPs with Arabic as the ML.

The most numerous categories in CPs with English as the matrix language are conjunctions (39.16\%), discourse markers (28.14\%) and adverbs (17.56\%). The difference in the two types of CPs lies not only in the categories used, but also in the patterns of code-switching. In CPs with English as the ML, code-switching is more conventionalized and less insertional than in CPs with Arabic as the ML. By 'conventionalized' I mean that it is more predictable in terms of the prevalence of specific items. The most recurrent conjunctions are $f a$ 'so' (21) and bass 'but' (22). In the category of discourse markers ya ' $n i$ 'it means' (23), which is typical of Egyptian Arabic native speakers, prevail.

(21) fa (so) a lot of them can't find jobs

(22) bass (but) you don't have an expire date

(23) couse ya'ni (I mean) I was so used to like this crazy life over there

Adverbs show greater variety compared to conjunctions and discourse markers. Their use seems to be related to the participants' preferences. However, the majority of them display a high frequency of occurrence in Egyptian Arabic, e.g. bar $u$ 'also' (24), àli 'at all' (25), a lan 'basically' (26) etc.

(24) bass (but) it's a matter of choice bar u (as well)

(25) ya'ni (I mean) they weren't accepting that āli (at all)

(26) which is a lan (basically) very expensive

Importantly, such items are not grammatically dependent elements. In contrast to nouns, adjectives and verbs, their use is not restricted by the lack of congruency between Arabic and English. Thus, they are not genuine insertions but rather represent a 
pattern of intra-sentential code-switching that is referred to by Muysken (1997; 2000; 2007) as alternational code-mixing.

Muysken distinguishes three types of code-mixing: insertion, alternation, and congruent lexicalization. Insertional code-mixing resembles the MLF model - i.e. a single constituent, be it a lexical item or a phrase, from language 1 is inserted into the grammatical structure of language 2 . It is characterized by a nested $a b a$ structure where ' $a$ ' stands for the ML and ' $b$ ' the EL. Inserted constituents are usually nouns and adjectives.

In alternation, on the other hand, there is no ML. This is when one language switches to the other without a structural relationship between the switched clusters that are usually longer than insertions and consist of several constituents. Alternation usually happens at the major clause boundary and involves, among others, conjunctions, adverbial modification or discourse marker switching which in Muysken (2007) was distinguished as a fourth type of code-mixing.

All the examples cited above (21-26) meet the conditions to be classified as alternations. This means that CPs with Arabic as the ML and CPs with English as the ML are different types of code-switching. This will be even more obvious if we look at multiword alternations that were initially classified according to the MLF model as EL islands.

\subsection{Embedded language islands}

\subsubsection{CPs with Arabic as the ML}

CPs with EL islands constitute 24.56 percent (600) of the total number of CPs with Arabic as the ML and 26.10 percent (396) of CPs with English as the ML. In CPs with Arabic as the ML, most EL islands are noun phrases. They are well-defined according to the rules of English - i.e. when modified by adjectives they follow English word order (27). Such phrases may occur with the articles a/an (28) and the (29). However, they are used inconsistently, as can be seen in (29) where the same phrase is repeated twice with the and then occurs with the Arabic il-.

(27) wi sa'āt law inta bi-ti-kallim bi l-proper accent and sometimes if you ASP-PFX.2SG-speak with the-proper accent And sometimes when you speak with the proper accent.

(28) fa fi - īn atta gabū-l-na an Arabic tutor so in the-China even brought.3PL-to-us an Arabic tutor So in China, they even brought us an Arabic tutor.

(29) 'arfīn this main street? 'arfīn this main street? il-main street illi barra da? knowing.PL this main street, knowing.PL this main street, the-main street that outside this?

Do you know this main street? Do you know this main street? The main street that is outside? 
As for the article $a$, it is barely used since Arabic lacks the indefinite article. Hence, the majority of noun phrases are inserted without the article, observing the rules of Arabic (30). However, the indefinite article is always present if a noun is preceded by the quantifier a lot (31):

(30) fïh Egyptian community kbīr f holanda there_is Egyptian community big in the_Netherlands There is a big Egyptian community in the Netherlands.

(31) a lot of the professors fa 'lan b-yi-nazzil-u l-level a lot of the professors really ASP-PFX.3-reduce-SFX.3p the-level A lot of the professors really reduce the level.

El islands are usually nested - i.e. they are inserted into the grammatical structure of Arabic. In (30) the word order of the phrase Egyptian community is English, although as a part of a larger phrase 'a big Egyptian community' is followed by the adjective kabir 'big' according to the rules of Arabic since Arabic is the ML of the whole CP.

Two types of English modifiers are always used in EL islands - possessive determiners (32) and numerals (33). This probably arises from the incongruence between Arabic and English. Possessive determiners in Arabic are enclitics which never appear with English items (similarly to suffixes in English verb inflection). Numerals in Arabic have a complex syntax - nouns that follow numerals may be used either in singular or plural depending on the numeral.

(32) ana masalan my friends miš b-yi-kallim-u English ktīr I for_example my friends NEG ASP-PFX-speak-SFX.3PL English much For example, my friends don't speak English a lot.

(33) ru na bi two minibuses went.2PL by two minibuses We went by two minibuses.

\subsubsection{CPS with English as $M L$}

In CPs with English as the ML, most EL islands are prepositional phrases (34) usually used in adverbial function and frozen expressions of high frequency of occurrence in Egyptian Arabic.

(34) fa (so) we stopped having classes together ba'di sana u-nu (after a year and a half)

However, most Arabic clusters that occur in English CPs are difficult to classify as 'real' insertions since they do not form single constituents - i.e. the elements that compose them are not syntactically related to each other. The majority of such clusters are combinations of three elements: adverbs, discourse markers and conjunctions. In 
(35) the cluster is composed of the conjunction bass 'but' and the discourse marker ya 'ni. In (36) the conjunction lākin 'but' with the adverb dilwa'ti 'now' occurs.

(35) bass ya 'ni (but I mean) it takes me a lot of efforts

(36) lākin dilwa’ti (but now) in our age a lot of people stop

The second most frequently occurring Arabic clusters are those that include personal pronouns:

(37) inn ana (that I) I'm betrayed as a friend

(38) ya'ni i na (I mean we) we invest a lot in weddings ya'ni (I mean)

(39) wa ya'ni humma (and I mean they) they can't afford

Personal pronouns mostly appear immediately before their English equivalents, resulting in pronoun doubling. The phenomenon seems to be typical of Arabic bilingual code-switching since it was observed in data from code-switching with French (Bentahila and Davies, 1983), Dutch (Nortier, 1990) as well as English (Eid, 1992; Okasha, 1999). Arabic personal pronouns before English pronouns also occur as lone elements (40).

\section{(40) i na (we) we're renting the house}

Myers-Scotton and her collaborators (Jake, 1994; Myers-Scotton, 2010; MyersScotton et al., 1996; Okasha, 1999) explain pronoun doubling as a consequence of the incongruence in the pronoun system of Arabic and English that serves as a predictable way to satisfy the requirements of English and Arabic. Muysken (2000: 181), on the other hand, states that pronoun doubling is an instance of alternation since the doubled pronoun appears in the left-dislocated position. Left-dislocation (not resulting in pronoun doubling) is very common in monolingual Egyptian. When a dislocated element is a pronoun it may precede, for example, a noun or prepositional phrase. A similar pattern is found in (41) and (42). In CPs with English as the ML left-dislocation includes not only pronouns. In (43), the phrase $b t \bar{u}{ }^{\prime} i l$-handasa is referred to again as they. In (44) the dislocated element ahli 'my family' appears in a longer monolingual cluster. Since switching between a noun and a verb, as can be found in (45), is possible, we state that left-dislocation (of nouns as well as pronouns) primarily serves pragmatic functions.

(41) ana (I) my school was expensive

(42) ya'ni i na for us he would have to be a Copt like me

(43) $b_{\mathrm{u}} \overline{\mathrm{c}}^{\prime}$ il-handasa (of.PL the-engineering, i.e. those in engineering) they used to speak more Arabic 
(44) bass ana ahli masalan (but I my family for example), they don't pray as much

(45) andnow il-banāt (the girls) are the majority

\section{Discussion}

The analysis thus far shows a clear discrepancy between the categories of items used in the two types of mixed CPs. In CPs with Arabic as the ML, the most commonly switched category is English nouns followed by adjectives and verbs. These categories, as open class words that easily accept new members, are the most frequently borrowed items. In CPs with English as the ML, the majority of switches are conjunctions, discourse markers followed by adverbs, nouns and personal pronouns. Thus, the open class words most numerously represented here are adverbs. Nouns, which clearly outnumber the other categories in CPs with Arabic as the ML, occur after conjunctions, discourse markers and adverbs. However, as mentioned, the relatively high number of nouns in CPs with English as the ML is due to one interview in which the majority of the recorded nouns appear. Adjectives constitute only one percent, while Arabic verbs do not occur at all. Therefore, with the exception of discourse markers and adverbs, closed class words prevail. The analysis of multiword-switches shows a similar tendency. English EL islands centre around nouns - i.e. they are mostly noun phrases. In CPs with English as the ML, the majority of multiword-switches are adverbial phrases and clusters consisting of conjunctions, discourse markers, adverbs and personal pronouns.

If we look only at the grammatical aspect of the results obtained, we have to admit that in general they corroborate both Myers-Scotton's and (to a lesser degree) Poplack's approach to borrowing as far as CPs with Arabic as the ML are concerned. If our point of reference is the nonce borrowing hypothesis, we should recognize most singly occurring items as instances of nonce borrowing since the majority are morphologically and syntactically integrated with Arabic. The phonological assimilation of the definite article $i l$ - to the subsequent item, which occurs on a regular basis, further supports this statement. This, however, does not include plurals, mostly inserted with the English suffix $-s$, as well as adjectives that occur as bare forms. The lack of morphological integration suggests that such items should be classified as code-switches which, on the other hand, contradicts the idea that most lone items from language 2 are nonce borrowings. In the data, there is only one item that happens to be pluralized with the Arabic -āt, i.e. kursāt 'courses'. However, it is used by the same participants interchangeably with its English equivalent. Thus, English plural nouns and adjectives inserted into Arabic seem to be the main challenge for the nonce borrowing hypothesis. 
Surprisingly, in Mustafawi's (2002) study, which is solely designed to test the hypothesis, the issue is omitted.

The morpho-syntactic integration is the reason for which the same insertions will be classified in the MLF model as either code-switches, conventionalized code-switches or core borrowed forms in the case of frequently recurrent and predictable items. Again, a problem occurs with plural items. A lot of them - e.g. classes, courses - occur recurrently and their use is predictable to a high degree (although their Arabic equivalents may appear as well). This indicates that they should be classified as conventionalized code-switches. The plural suffix $-s$ is categorized under the $4 \mathrm{M}$ model as belonging to early system morphemes that are indirectly selected by content morphemes to specify their meaning (see e.g. Jake and Myers-Scotton, 2009). Thus, its occurrence in CPs with Arabic as the ML does not contradict the main premise of the MLF model - that of the asymmetrical distribution of content and system morphemes.

However, a more detailed analysis of lone items as well as compound nouns, indicates that in fact they are borrowings. This is not to say that they are widely accepted by monolingual speakers. On the contrary, they are comprehensible only by fluent bilinguals becoming, however, part of their mental lexicon. In the speech of those speakers they function as borrowed items mainly due to their bilingual education paired with the linguistic situation in Egypt.

The majority of inserted nouns relate broadly to the academic life or fields associated with Standard Arabic in monolingual discourse. The structural context in which they appear shows that they do not always fill lexical gaps since the participants seem to know their Arabic equivalents. This may suggest that inserted nouns are indeed code-switches. However, there are still a lot of instances that lack gender congruence indicating the lack of their Arabic equivalents at the speakers' disposal.

According to the participants' testimonies, they use English items, compound nouns as well as expressions (e.g. have a nice day) for two reasons. In a lot of circumstances, they are the only forms accessible to them due to their education in English and exposure to American popular culture since their childhood. Lewko (2012) found similar statements in his interviews with AUC students which confirms the universality of the phenomenon in the AUC community. Some participants in the present study even claimed that they had to use English to convey specific meanings since Arabic did not provide them (even if in reality they do exist in Arabic). The second reason is that some Arabic items/expressions are perceived as inappropriate since they do not cover the exact meaning connoted by their English equivalents. This also includes items that seem to have exact equivalents in Arabic - e.g. anthropology.

For the majority of the participants, raised in and accustomed to the two languages, code-switching is a natural way of communicating with others. The participants stressed that they do so subconsciously:

"It's very natural, I mean, for the first time I paid attention that I spoke English and Arabic in the same sentence when foreigners asked me, 'Why are you speaking like that?' For me it's a need [...] when I meet somebody I automatically know which language to speak, I don't think, I mean, the process for me is very natural." 
Speaking in monolingual Arabic as well as monolingual English is certainly an uncomfortable challenge. One participant explained his experiences while dealing with monolingual Arabic speakers as follows:

"I have to translate it in my head, so the best, like I'm most comfortable and most confident with people who speak both [Arabic and English] because I can then like navigate freely but otherwise when I feel like I'm constrained by just one language."

Such statements paired with the analysis of the participants' linguistic behaviour (in terms of grammar as well as pragmatics) indicate that both Arabic and English are part of their mental lexicon. Due to their bilingual education and exposure to two different cultures they are aware of the cognitive differences between the two cultures and the languages that relate the cultures. English is often used to covey messages related to more serious topics and to do so in a precise and effortless way. Moreover, their type of formal education makes them unfamiliar with Arabic items that belong to the domain of Standard Arabic although they are fluent in vernacular. Thus, the majority of items/compound nouns that occur in CPs with Arabic as the ML are in fact borrowings since in reality they fill lexical gaps as well cultural ones that relate to the two languages.

We claim that this also includes items pluralized with $-s$. Rouchdy (1992) states that educated speakers tend to use English plural items with $-s$ as opposed to the semieducated who resort to the Arabic suffix $-\bar{a} t$. The author recognizes morphological integration of plurals as a decisive factor in the differentiation between code-switching and borrowing and hence classifies the first phenomenon as code-switching and the second one as borrowing. The term 'educated' refers to communicative bilinguals in both languages. Therefore, the linguistic profile of the participants in the present study more or less corresponds with that of the participants in Rouchdy's study. This may indicate that English plurals are typical of fluent bilinguals regardless of whether they are code-switches or instances of borrowing.

The discrepancy between the two types of CPs further supports the claim that the majority of lone English items are borrowings. Arabic lone morphemes are functional items (conjunction, pronouns), discourse markers and adverbs. Typical EL islands - i.e. those that show an internal structural relationship - form the minority. Longer Arabic clusters are composed of function words, discourse markers and adverbs. As such, they are not insertions but alternations. According to Muysken, this type of code-switching is especially frequent in stable bilingual communities with a tradition of language separation while insertion is typical of communities in which speakers are not equally proficient in the two languages - e.g. recent migrant communities. A similar phenomenon is also found in the AUC community. AUC students do not constitute a monolithic community in terms of their education and backgrounds as is often claimed. Besides those educated in schools with foreign languages in Egypt, there are also students who lived abroad most of their lives as well as those who went to public schools. The type of exposure to English, their linguistic behaviour outside the AUC 
and so on clearly affects the patterns of code-switching they use. Insertional codeswitching with Arabic as the ML is the only one that appears in the speech of all students including graduates of public schools. Alternation, on the other hand, is typical of bilinguals with long-term exposure to English and almost the only one type of codeswitching used by those who feel more comfortable speaking English.

These differences in patterns of switching between Arabic and English may indicate that the two languages are used for specific pragmatic reasons. While insertional codeswitching is used primarily for lexical references, alternation allows the discourse to be adapted to the local environment in a relatively easy way. Such embedding is desirable for a variety of reasons - for example, while discussing religious issues that are traditionally associated with Standard Arabic. More detailed pragmatic analysis, which is beyond the scope of the study, shows further evidence for the distributional and functional asymmetry between Arabic and English which argues for the claim that English is taking over particular fields attributed to Standard Arabic in monolingual discourse. Thus, we should conclude that the AUC community is diglossic in a broader sense of diglossia (so-called extended diglossia, see Fishman, 1967) where the two varieties of a language are replaced by two unrelated languages - i.e. Egyptian Arabic and English. Since English supplies mainly the lexical needs that arise from bilinguals' socio-linguistic and cultural background, the majority of English lone insertions in Arabic should be acknowledged as borrowed rather than code-switched items even though they are not established loans.

\section{Conclusion}

The study aimed to determine whether lone English items in Arabic-English codeswitching are borrowed forms or code-switches. Our hypothesis was that the majority of such items would constitute borrowed forms due to the linguistic situation in Egypt. The hypothesis was tested within the framework of the MLF model. Two types of bilingual CPs were investigated - CPs with Arabic as the ML and CPs with English as the ML. A comparative analysis demonstrated that the two types of CPs differ in the categories of morphemes used. English provides nouns, adjectives and verbs. The majority of them relate to fields that are associated with Standard Arabic in monolingual discourse. According to the participants in the study, their use is determined by the speakers' insufficient knowledge of Standard Arabic due to their education in schools with instruction in English and their life-long exposure to Western culture and media. Thus, English items primarily fulfil the lexical needs to supplement the bilinguals' vocabulary and, hence, should be classified as borrowed items. In previous studies, the morphological integration to the dominant language was seen as a pivotal factor in the differentiation between code-switching and borrowing. The results of the study show that it is not always preserved in the data. This includes plural items, adjectives and, to some extent, verbs. These categories are either suffixed with the English $-s$ (plural nouns), used as bare forms without a feminine marker (adjective), or partially inflected by Arabic prefixes but not suffixes (verbs). We state that the lack of 
morphological integration results from the incongruence between the two languages. The participants in the study are proficient bilinguals, aware of the structural differences between Arabic and English. This, in turn, translates into a partial integration of borrowed items. Therefore, we believe that the analysis of code-switching vs. borrowing should incorporate the structural characteristics of the languages involved, functional dimension, the speakers' sociolinguistic and psycholinguistic background, and the local linguistic situation.

\section{Notes}

1. The research was financed by the National Science Center in Poland based on decision number DEC-2013/11/D/HS2/04524. The data were collected and transcribed with coresearcher Magdalena Zawrotna.

2. In the MLF model, mixed CPs must conform to two fundamental principles - the Morpheme Order Principle and the System Morpheme Principle. The first one defines the ML as the only one that supplies the word order of a CP. The System Morpheme Principle (supported by the 4-M model) prohibits the occurrence of EL outsider system morphemes, typically subject-verb agreement and case-marking, that "coindex relations that hold across phrase and clause boundaries" (Jake and Myers-Scotton 2009: 225). If either of these two principles is not satisfied, neither of the languages can be defined as the ML; the result is a composite ML with two languages providing the grammatical structure. This is the case in the example below. The CP exemplifies a typical Arabic nominal sentence expressing possession with Arabic suppling all outsider system morphemes. However, the word order of the phrase 'arabi classes observes the rules of English, which violates the Morpheme Order Principle. Thus, the $\mathrm{CP}$ is simultaneously framed by the two languages. We decided to exclude such CPs for the sake of the clarity of the analysis, especially that they are few in number in the data.

kān 'and-ina 'arabi classes

was.1MASC with-our Arabic.MSC.SG classes

We had Arabic classes.

\section{References}

Aabi, Mustapha (1999): The Syntax of Moroccan Arabic/French and Moroccan Arabic/Standard Arabic Code Switching. PhD dissertation. University of Sheffield.

Adalar, Nevin, and Sali Tagliamonte (1998): "Borrowed nouns; bilingual people: The case of the 'Londrali' in Northern Cyprus". International Journal of Bilingualism, 2(2): 139-159.

Al-Enazi, Mohamed Husein (2002): The Syntactic Form and Social Functions of Saudi ArabicEnglish Code-Switching among Bilingual Saudis in the United States. PhD dissertation. Indiana University of Pennsylvania. 
Alenezi, Farah H. (2006): Formal Constraints on Arabic/English Code-Switching: A LexicallyBased Approach. PhD dissertation. University of Kansas.

Al-Khatib, Hayat (2003): "Language alternation among Arabic and English youth bilinguals: Reflecting or constructing social realities?" International Journal of Bilingual Education and Bilingualism, 6(6): 409-422.

Al-Mansour, Nasser Saleh (1998): Linguistic Constraints on Code-Switching: A Case Study of Saudi-Spoken Arabic English Code-Switching. PhD dissertation. University of Florida.

Al-Rowais, Hawazen. (2012): Code Switching between Arabic and English, Social Motivations and Structural Constraints. PhD dissertation. Ball State University.

Atawneh, Ahmad (1992): "Codemixing in Arabic-English bilinguals". In E. Broselow et al., eds., Perspectives on Arabic Linguistics IV: Papers from the Fourth Annual Symposium on Arabic Linguistics. Amsterdam/Philadephia: John Benjamins Publishing, 219-241.

Badawi, El-Said M. (1973): Mustawayāt Al-Lu a Al-'arabiyya Al-Mu'a ira F̄̄ Mi r. $\mathrm{PhD}$ disseratattion. Dār al-ma‘ārif.

Bader, Yousef (1995): "Code-Switching to English in daily conversations in Jordan: factors and attitudes". Abhath Al-Yarmouk, 13(2): 9-27.

Bader, Yousef (1998): "Lexical codeswitching in the speech of an Arabic- English bilingual child". Interface, 13(1): 3-17.

Bader, Yousef, and Denise D. Minnis (2000): "Morphological and syntactic code-switching in the speech of an Arabic-English bilingual child". Multilingua, 19(4): 383-404.

Bassiouney, Reem (2006): Functions of Code Switching in Egypt: Evidence from Monologues. Boston: Brill.

Bentahila, Abdelali, and Eirlys E. Davies (1992): "Codeswitching and language dominance". In R. J. Harris, ed., Cognitive Processing in Bilinguals. North-Holland Distributors for the U.S. and Canada: Elsevier Science Publishing, 443-457.

Bentahila, Abdelali, and Eirlys E. Davies. (1991): Constraints on Codeswitchig: A Look beyond Grammar. Vol. 2. Barcelona: European Science Foundation.

Bentahila, Abdelali, and Eirlys E. Davies. (1983): "The syntax of Arabic-French codeswitching". Lingua, 59(4): 301-330.

Boumans, Louis (1998): The Syntax of Codeswitching: Analysing Moroccan Arabic/Dutch Conversations. PhD dissertation. Tilburg University Press.

Boussofara-Omar, Naima (2003): "Revisiting Arabic diglossic switching in light of the MLF model and its sub-models: The 4-M model and the abstract level model". Bilingualism: Language and Cognition, 6(1): 33-46.

Budzhak-Jones, Svitlana (1998): "Developing diagnostics: Word-internal code-switching versus borrowing". Cahiers Linguistiques d'Ottawa, 26: 1-14.

Budzhak-Jones, Svitlana, and Shana Poplack (1997): "Two generations, Two strategies: The tate of bare English-origin nouns in Ukrainian". Journal of Sociolinguistics, 2(1): 225-258.

Eid, Mushira (1992): "Directionality in Arabic-English codeswitching". In A. Rouchdy, ed., The Arabic Language in America. Detroit: Wayne State University Press, 50-71.

Eze, Ejike (1998): "Lending credence to a borrowing analysis: Lone English-origin incorporations in Igbo discourse". International Journal of Bilingualism, 2(2): 83-201.

Ferguson, Charles A. (1959): "Diglossia". Word, 15: 325-340.

Fishman, Joshua. (1967): "Bilingualism with and without diglossia; diglossia with and without bilingualism.”. Journal of Social Issues, 23(2): 29-38.

Galegher, Erica Lynn. (2012): Thank You, Merci, Shukran! Private Education and Language Egypt. Cairo: The American University in Cairo. https://dar.aucegypt.edu/handle/10526/3135. 
Haeri, Niloofar (1997): "The reproduction of symbolic capital: Language, state, and class in Egypt". Current Anthropology, 38(5): 795-816.

Hary, Benjamin. (1996): "The Importance of the Language continuum in Arabic multiglossia". In A. Elgibali, ed., Understanding Arabic: Essays in Contemporary Arabic Linguistics in Honor of El-Said Badawi. Cairo: The American University in Cairo Press, 69-90.

Heath, Jeffrey (1989): From Code-Switching to Borrowing: Foreign and Diglossic Mixing in Moroccan Arabic. London: Kegan Paul International.

Hussein, Riyad Fayez, and Ghazi A. Shorrab (1993): "Syntactic constraints on the code switching of Arabic-English bilinguals". International Review of Applied Linguistics in Language Teaching, 31(3): 236-241.

Jake, Janice (1994): "Intrasentential codeswitching and pronouns: On the categorial status of function elements". Linguistics, 32: 271-298.

Jake, Janice L. and Carol Myers-Scotton (2009): "Which Language? Participation potentials across lexical categories in codeswitching”. In L. Isurin et al., eds., Multidisciplinary Approaches to Code Switching. Amsterdam/Philadelphia: John Benjamins Publishing, 207242.

Koning, Anouk de (2009): Global Dreams: Class, Gender, and Public Space in Cosmopolitan Cairo. Cairo: The American University in Cairo Press.

Lewko, Alexander (2012): Linguistic Projection and the Ownership of English: Solidarity and Power with the English Language in Egypt. MA dissertation. Cairo: The American University in Cairo Press.

Mehrez, Samia. (2010): Egypt's Culture Wars: Politics and Practice. Cairo: The American University in Cairo Press.

Mejdell, Gunvor (2006): Mixed Styles in Spoken Arabic in Egypt: Somewhere between Order and Chaos. Boston: Brill.

Mitchell, Terence F. (1986): "What is educated spoken Arabic?" International Journal of the Sociology of Language, 16(1): 7-32.

Mohamed, Fatma. (1989): Arabic-English Code-Switching in the Speech of an Egyptian Child. University of Pennsylvania.

Mustafa, Zahra, and Mahmoud Al-Khatib (1994): "Code-mixing of Arabic and English in teaching science". World Englishes, 13(2): 215-224.

Mustafawi, Eiman (2002): "Lone English-origin nouns in Arabic: Codeswitchers or borrowings?" In S. Burelle and S. Somesfalean, eds., Actes Du Congrès Annuel de l'Association Canadienne de Linguistique 2002/Proceedings of the 2002 Annual Conference of the Canadian Linguistic Association. Université du Québec à Montréal, Département de linguistique et de didactique des langues, 219-231.

Muysken, Pieter (2000): Bilingual Speech: A Typology of Code-Mixing. Kindle Edition, Cambridge: Cambridge University Press.

Muysken, Pieter (1997): "Code-switching processes: alternation, insertion, congruent lexicalization". In M. Pütz, ed., Language Choices: Conditions, Constraints, and Consequences. Amsterdam/Philadelphia: John Benjamins Publishing, 361-380.

Muysken, Pieter (2007): "Mixed codes". In P. Auer and W. Li, Handbook of Multilingualism and Multilingual Communication. Berlin: Mouton de Gruyter, 315-339.

Myers-Scotton, Carol (1998): "A way to dusty death: the matrix language turnover hypothesis". In L. A. Grenoble and L. Whaley, eds., Endangered Languages. Cambridge: Cambridge University Press, 289-316. 
Myers-Scotton, Carol (1992): "Comparing codeswitching and borrowing”. In C. M. Eastman, ed., Codeswitching. Clevedon, Philadelphia, Adelaide: Multilingual Matters Ltd, 19-39.

Myers-Scotton, Carol (1993): Duelling Languages: Grammatical Structure in Codeswitching. Oxford: Oxford University Press.

Myers-Scotton, Carol. (2006): Multiple Voices: An Introduction to Bilingualism. Oxford: Blackwell Publishing.

Myers-Scotton, Carol (2010): "Patterns and predictions for code-switching with Arabic". In R. Bassiouney, ed., Arabic and the Media. Leiden: Brill, 81-95.

Myers-Scotton, Carol, and Janice Jake (2009): "A Universal model of code-switching and bilingual language processing and production”. In B. E. Bullock and A. J. Toribio, eds., The Cambridge Handbook of Linguistic Code-Switching. Cambridge: Cambridge University Press, 336-357.

Myers-Scotton, Carol et al. (1996): "Arabic and constraints on codeswitching". In M. Eid and D. Parkinson, eds., Perspectives on Arabic Linguistics IX: Papers from The Ninth Annual Symposium on Arabic Linguistics. Amsterdam/Philadelphia: John Benjamins Publishing, 943.

Nortier, Jacomien (1990): Dutch-Moroccan Arabic Code-Switching among Young Moroccans in the Netherlands. Dordrecht: Foris.

Okasha, Maha (1999): Structural Constraints on Arabic/English Codeswitching. PhD dissertation. South Carolina: University of South Carolina.

Poplack, Shana (1980): "Sometimes I'll start a sentence in Spanish Y TERMINO EN ESPAÑOL: Toward a Typology of Code-switching”. Linguistics, 18(7/8): 581-618.

Poplack, Shana (1993): "Variation theory and language contact". In D. R. Preston, ed., American Dialect Research. Centennial Series of the American Dialect Society, Amsterdam/Philadelphia: John Benjamins Publishing, 251-286.

Poplack, Shana, and Marjory Meechan (1998): "Introduction: How languages fit together in codemixing". International Journal of Bilingualism, 2(2): 127-138.

Poplack, Shana et al. (1988): "The social correlates and linguistic processes of lexical borrowing and assimilation". Linguistics, 26: 47-104.

Poplack, Shana et al. (1989): "Distinguishing language contact phenomena: evidence from Finnish-English Bilingualism". World Englishes, 8(3): 389-406.

Rouchdy, Aleya (1992): "Borrowing in Arab-American Speech". In A. Rouchdy, ed., The Arabic Language in America. Detroit: Wayne State University Press, 36-9.

Sallo, Ibrahim Khidhir (1994): "Arabic-English code-switching at the University: A Sociolinguistic Study". In R. de Beaugrande et al., eds., Language, Discourse and Translation in the West and Middle East. Amsterdam/Philadelphia: John Benjamins, 115-131.

Sankoff, David, et al. (1990): "The Case of the nonce loan in Tamil". Language Variation and Change, 2: 71-101.

Schaub, Mark (2000): "English in the Arab Republic of Egypt". World Englishes, 19(2): 225238.

Turpin, Danielle (1998): "Le Français, c'est le last frontier": The Status of English-Origin Nouns in Acadian French". International Journal of Bilingualism, 2(2): 203-219. 